\title{
MACLEYA CORDATA AND PRUNELLA VULGARIS IN ORAL HYGIENE PRODUCTS - THEIR EFFICACY IN THE CONTROL OF GINGIVITIS
}

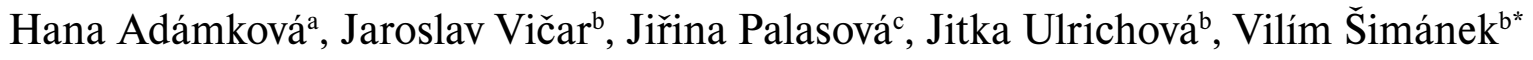 \\ ${ }^{a} I^{\text {st }}$ Clinic of Dentistry, Faculty of Medicine, Palacký University, Czech Republic \\ ${ }^{b}$ Institute of Medical Chemistry and Biochemistry, Faculty of Medicine, Palacký University, 77515 Olomouc, \\ vilim@tunw.upol.cz \\ c Dental Surgery, Mikulášská 27, 79401 Krnov
}

Received: May 12, 2004; Accepted July 6, 2004

Key words: Macleya cordata/Prunella vulgaris/Dentifrice/Antimicrobial/Anti-inflammatory/Gingivitis

A double-blind, placebo-controlled clinical trial was performed to investigate the effectiveness of a herbal-based dentifrice in the control of gingivitis. Forty volunteers completed the 84-day study. All subjects were balanced for parameters measured - plaque index (PI), community periodontal index of treatment needs (CPITN) and papillary bleeding index (PBI). The dentifrice was effective in reducing symptoms of gingivitis as evaluated by the CPITN and PBI indexes.

\section{INTRODUCTION}

In oral hygiene preparations, toothpastes, massage gels, mouthrinses, prevailing active components are synthetic substances such as antimicrobially active benzydamine hydrochloride (1-benzyl-[3-(dimethylamino) propoxyl]-1 $H$-indazole), cetylpyridinium chloride, chlorhexidine digluconate (1,6-di(4'-chlorophenyldiguanido) hexane digluconate), triclosan (5-chloro-2-2,4-dichlorophenoxy)phenol) and zinc chloride or stannous fluoride. Another important market segment is formed by preparations containing as active components, medicinal plants reputed for their anti-inflammatory and antimicrobial activity. Herbal products of this kind traditionally contain plant extracts and/or pure components including chamomile, echinacea, peppermint oil, sage, myrrh, green tea bioflavonoids, gallotannins and substances such as allantoin, coenzyme $\mathrm{Q}_{10}$, bisabolol, guaiazulene, eugenol, and eucalyptus essential oil (thymol and eucalyptol, mixed with menthol and methyl salicylate) (ref.'). In comparison to the above-mentioned synthetic products, however plant extracts and/or components are less efficient following single application.

Recently, we have studied the biological activity of an extract of Prunella vulgaris L. (Labiatae), and we found marked cytoprotective, antioxidant/radical scavenging, antiviral and anti-inflammatory effects both in vitro and in vivo ${ }^{2}$. This plant, known as the "self-heal", was popular in traditional European medicine during the $17^{\text {th }}$ century as a remedy for alleviating sore throat, reducing fever, and accelerating wound healing ${ }^{3}$. A major constituent of $P$. vulgaris is rosmarinic acid, a phenolic antioxidant whose content can be as high as $6 \%$ (ref. ${ }^{4}$ ). Phytochemical studies indicate that $P$. vulgaris further contains oleanolic, betulinic, ursolic, $2 \alpha, 3 \alpha$-dihydroxyurs-12-en-28-oic and $2 \alpha, 3 \alpha$-ursolic acids, triterpenoids, flavonoids, tannins and anionic polysaccharide prunelline ${ }^{5}$. Isoquinoline alkaloids from Macleya cordata R. Br. (Papaveraceae) are another group of biologically active components studied recently in this laboratory. The main alkaloids of this plant, quaternary benzo[c]phenanthridines (QBA) sanguinarine and chelerythrine are among the antimicrobially most active of natural substances. These alkaloids display a plethora of species- and tissue-specific actions but the molecular basis of their pharmacological activities remains obscure ${ }^{6}$. They exhibit antimicrobial, antiinflammatory, antimitotic, adrenolytic, sympatholytic, cytostatic and local anesthetic effects? ${ }^{7}$. Medicinal plants Sanguinaria canadensis and Chelidonium majus (Papaveraceae) containing both alkaloids were in the past, utilized in traditional medicine (North America, Europe, China). QBA fractions from S. canadensis - sanguinaria and $M$. cordata - sanguiritrin are used in toothpastes and mouthwashes as antiplaque agents. Sanguinarine as well as extracts containing benzo[c]phenanthridine alkaloids exhibit very low acute oral toxicity $\left(\mathrm{LD}_{50} 1.7\right.$, and $1.4 \mathrm{~g} /$ $\mathrm{kg}$, resp.; rat); in subchronic studies, minor evidence of treatment-related toxicity of QBA (doses > $30 \mathrm{mg} / \mathrm{kg} /$ day; rat, monkey) has been reported (summarized in ref. $^{7}$ ). The cytotoxicity of sanguinarine was assessed on human S-G gingival cells and human HGF-1 gingival fibroblasts in an in vitro experiment; the 24 hours cytotoxicity was comparable to that of chlorhexidine ${ }^{8}$. The available data do not predict a health hazard to humans when QBAcontaining oral hygiene products are used. On the other hand, it has been reported by a single group of authors that long-term use (5 years) of oral products containing $0.03 \%$ of sanguinaria is compromised by increased prevalence of maxillary vestibule leukoplakia9. 
The aim of this study was to assess the efficacy of a dentifrice containing $M$. cordata and $P$. vulgaris extracts in the control of gingivitis.

\section{MATERIAL AND METHODS}

Ethical approval for the clinical trial was provided by the Ethical Committee of the Teaching Hospital, Olomouc. A total of 40 subjects ( 18 female and 22 male) aged between 34 and 58 years were selected for the study. They had to manifest gingivitis as defined by bleeding on gentle probing at more than $60 \%$ of the sites examined and no periodontal pockets greater than $3 \mathrm{~mm}$. Informed written consent to participate in the study was obtained from each subject. All subjects were healthy and none were undergoing antibiotic or anti-inflammatory therapy or had undergone such therapy in the previous six months. Female subjects were neither pregnant nor taking the contraceptive pill. No subject had a history of known sensitivity or oral mucosal tissue reaction to toothpaste. The tested toothpaste contained $P$. vulgaris extract (0.5\%), $M$. cordata extract $(0.005 \%)$, a silica abrasive system, humectants and surfactants, but no fluoride. The placebo did not contain plant extracts. Since gingivitis subjects complain of over-sensitivity of periodontal tissues, the evaluation

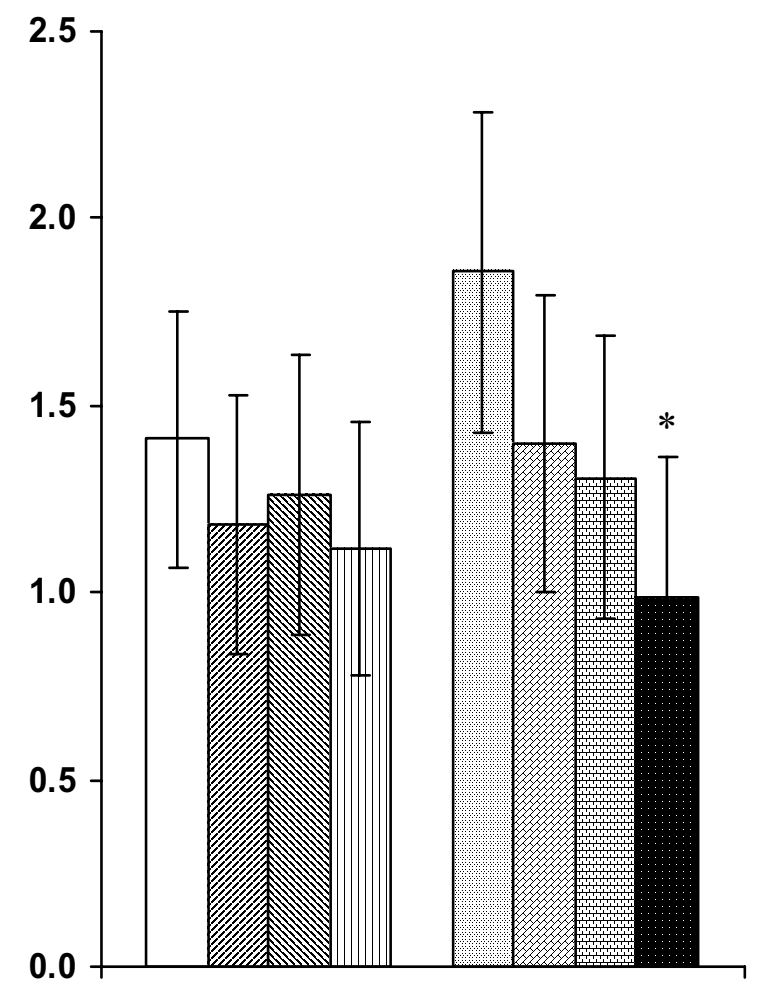

Fig. 1. The mean (standard deviation) of community periodontal index of treatment needs (CPITN). * Significant decrerase from baseline to final (12-week) examination $\mathrm{p}<0.05$. of subjective sensations was also included in the study. At baseline examination, the condition of the periodontium was evaluated using indexes CPITN (Community Periodontal Index of Treatment Needs - states the presence of bleeding, calculus, local irritating factors and the depth of periodontal pockets), PBI (Papillary Bleeding Index - degree of gingival bleeding around all teeth), and the level of oral hygiene was assessed using the PI index (Plaque Index - amount of plaque on the tooth surface). The subject's sensations were recorded. All subjects were then divided randomly to two equal groups. At baseline, they were instructed in detail to follow the guidelines of good oral hygiene. After scaling, they received the toothpaste, test sample or placebo according to a random code by which double blinding was maintained and two toothbrushes. On the first follow-up visit (day 14), the condition of periodontium and oral cavity was evaluated, and subjective sensations of the participant were recorded. The second and third follow-up visits (day 42 and 84, resp.) took place in the same way. Prior to the final clinical assessment, the subjects were asked not to discuss the characteristics of the dentifrice that they had used with the examiner (J.P.). Data are expressed as mean \pm S.D. The significance of differences among four visits for each index (PI, CPITN and PBI) was analyzed by a one-way analysis variance (ANOVA). The level of confidence required for significance was selected at $\mathrm{p}<0.05$.

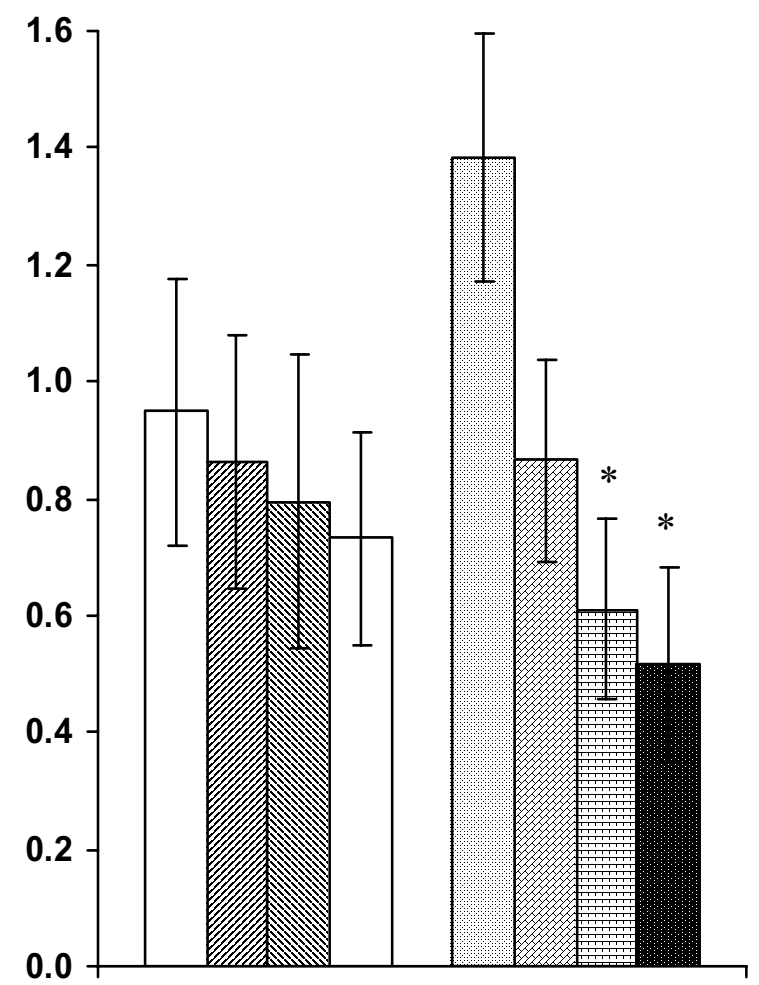

Fig. 2. The mean (standard deviation) of papillary bleeding index (PBI). * Significant decrease from baseline to second and final (6- and 12-week) examination $\mathrm{p}<0.05$. 


\section{RESULTS AND DISCUSSION}

The PI values both in mandible and maxilla decreased in the test group from 0.47 to 0.10 (average of both jaws); in the placebo group they decreased as well, from 0.381 to 0.16 . We ascribe the improvement in the PI index, which is comparable in both groups, to better oral hygiene all patients applied in the course of the study. In indexes CPTIN (Fig. 1) and PBI (Fig. 2), there was a statistically significant $(\mathrm{p}<0.05)$ improvement in the test group, for the CPITN from 1.86 to 0.98 and for the PBI from 1.38 to 0.52 . In the placebo group, there was also an improvement in both indexes (CPITN from 1.41 to 1.12; PBI from 0.95 to 0.73 ), again this can be ascribed to better oral hygiene in the course of the study, but the improvement in this case was not statistically significant. Subjective sensation and tolerance of the herbal-based toothpaste by the participants were good.

The professional community generally accepts the fact that a mechanical tooth brushing effect is positively affected by dentifrice components with antimicrobial, anti-inflammatory and healing effects. However, studies confirm oriented to evidence this often bring in mixed results, particularly if a concomitant use of a dentifrice and a mouthrinse is clinically studied ${ }^{10}$. Most dentifrices containing an active component claim an antiplaque effect. This is true particularly for synthetic components with the exception of chlorhexidine whose antimicrobial efficiency is eliminated by necessary detergents. Oral hygiene preparations containing herbal components are generally less efficient than those containing synthetic substances. On the other hand, their advantage is that they frequently combine several positive effects such as anti-inflammatory, antimicrobial and healing. The composition of the tested dentifrice originated in the long-known antimicrobial activity of sanguinarine and chelerythrine ${ }^{11}$ and in in vitro and in vivo evidenced antioxidative and anti-inflammatory effects of $P$. vulgaris $^{12}$. The results of this clinical study demonstrate a statistically confirmed anti-inflammatory effect of the herbal-based dentifrice; but not demonstrated antiplaque effect.

\section{CONCLUSION}

In the current population, a growing percentage of people prefer oral hygiene preparations containing medicinal plant extracts and/or their components. This study showed that the combination of $M$. cordata and $P$. vulgaris extracts was efficient in the control of gingivitis. It was concluded therefore that our herbal based preparation may offer an efficacious alternative to conventional dentifrice formulations in a market where there is an increasing interest in naturally based medicinal products.

\section{ACKNOWLEDGEMENT}

Supported by grant MSM 151100003.

\section{REFERENCES}

1. Mandel ID. (Editor) (1994) A symposium on current and future uses of antimicrobial mouthrinses. JADA 125, 2-S-32-S.

2. Psotová J, Lasovský J, Vičar J. (2003) Metal-chelating properties, electrochemical behavior, scavenging and cytoprotective activities of six natural phenolics. Biomed Papers 147, 147-153.

3. Marková H, Soušek J, Ulrichová J. (1997) Prunella vulgaris L. - a rediscovered medical plant. Čes a Slov Farm 46, 58-63.

4. Lamaison JL, Petitjean-Freytet C, Carnat A. (1991) Medicinal Laminaceae with antioxidant properties, a potential source of rosmarinic acid. Pharm Acta Helv 66, 185-188.

5. Holzmannová V. (1996) Rosmarinic acid and its biological activity. Chem Listy 90, 486-496.

6. Šimánek V, Vespalec R, Šedo A, Ulrichová J, Vičar J. (2003) Quaternary benzo[c]phenanthridine alkaloids - Biological activities. In Chemical Probes in Biology (M.P. Schneider, ed.). NATO Science Series, II. Mathematics, Physics and Chemistry - 129. Kluwer Academic Publishers, Dordrecht. 245-254.

7. Walterová D, Ulrichová J, Válka I, Vičar J, Vavrečková C, Táborská E, Harkrader RJ, Meyer DL, Černá H, Šimánek V. (1995) Benzo[c]phenanthridine alkaloids sanguinarine and chelerythrine: biological activities and dental care applications. Acta Univ Palacki Olomuc (Olomouc), Fac. Med. 139, 7-16.

8. Babich H, Zuckerbraun HL, Barber IB, Babich SB, Borenfreund E. (1996) Cytotoxicity of Sanguinarine Chloride to Cultured Human Cells from Oral Tissue. Pharm Toxicol 78, 397-403.

9. Mascarenhas AK, Allen CM, Moeschbergr ML. (2002) The association between Viadent use and oral leukoplakia - results of a matched case-control study. J Public Health Dent 62, 158-162.

10. Eley BM. (1999) Antibacterial agents in the control of supragingival plaque - a review. Brit Dent J 186, 286-296.

11. Yiu CKY, Wei SHY. (1993) Clinical efficacy of dentifrices in the control of calculus, plaque and gingivitis. Quintessence Inter 24, 181-188.

12. Škottová N, Kazdová L, Oliyarnuk O, Večeřa R, Sobolová L, Ulrichová J. (2004) Phenolics-rich extracts from Silybum marianum and Prunella vulgaris reduce a high-sucrose diet induced oxidative stree in hereditary hypertriglyceridemic rats. Pharm Res $50,123-130$ 